\title{
Cr speciation \& isotope composition in seawater
}

\author{
A.B. DAVIDSON ${ }^{1 *}$, R. FRANCOIS $^{1}, \&$ S.A. CROWE ${ }^{1,2}$ \\ ${ }^{1}$ Department of Earth, Ocean, and Atmospheric Sciences, \\ Univeristy of British Columbia, Vancouver, British \\ Columbia, Canada \\ (*correspondence: adavidso@eos.ubc.ca) \\ ${ }^{2}$ Department of Microbiology \& Immunology, University \\ of British Columbia, Vancouver, British Columbia, \\ Canada
}

Chromium (Cr) stable isotopes are fractionated during redox reactions between the two naturally occuring species, $\mathrm{Cr}(\mathrm{III})$ and $\mathrm{Cr}(\mathrm{VI})$. Manganese oxides are required for the production of $\mathrm{Cr}(\mathrm{VI})$, which themselves are produced by reaction with oxygen. $\mathrm{Cr}$ isotopes are thus a powerful paleo redox proxy. $\mathrm{Cr}$ is subject to extensive redox cycling between weathering and eventual burial in sedimentary deposits, and the effects of this cycling on $\mathrm{Cr}$ isotope compositions is currently hard to predict. A large area of uncertainty is the effect of $\mathrm{Cr}$ redox reactions within seawater itself.

Several studies of $\mathrm{Cr}$ isotopes in seawater in recent years are shedding new light on $\mathrm{Cr}$ isotope behaviour in the welloxygenated, open ocean water column. Most of these studies have focused on measurements of total $\mathrm{Cr}$ [e.g. 1]. More information exists, however, in combined analyses of $\mathrm{Cr}$ isotopes in both species [2, 3], though these measurements remain challenging and with little basis for cross-comparison owing to scarcity in data.

Here, we present a series of species-specific $\mathrm{Cr}$ isotope measurements in seawater from coastal British Columbia, Canada, using a new $\mathrm{Mg}(\mathrm{OH})_{2}$ coprecipitation method [3]. These measurements reveal how $\mathrm{Cr}$ speciation and the isotopes of each species change under a broad range of geochemical conditions. $\delta^{53} \mathrm{Cr}(\mathrm{III})$ is consistently more negative than $\delta^{53} \mathrm{Cr}$ (tot), and thus the calculated $\delta^{53} \mathrm{Cr}(\mathrm{VI})$ is more positive, as would be predicted based on the known directionalty of fractionation during reduction. There is, however, a wealth of structure in the species-specific isotope profiles, which may provide new information on the controls on $\delta^{53} \mathrm{Cr}$ in the oceans and the $\mathrm{Cr}$ isotope record in marine sediments.

[1] Rickli et al., (2019). Geochimica et Cosmochimica Acta, 262, 188-206. [2] Wang et al., (2019). Geochemistry, Geophysics, Geosystems, 20, 2499-2514. [3] Davidson et al., (2020). Limnology and Oceanography: Methods, 18(1), 8-19. 